\title{
SYMPTOM PRESCRIPTION: A REVIEW OF THE CLINICAL OUTCOME LITERATURE
}

\author{
Joel Katz
}

McGIII University

\begin{abstract}
The concept of symptom prescription is introduced and defined with examples. The clinical outcome literature on the use of symptom prescription as a therapeutic technique designed to facilitate symptom reduction is reviewed. It is concluded that prescribing the symptom is an effective technique for individuals complaining of sleep onset insomnia. In especially resistant cases, symptom prescription may prove to be the treatment of choice. Generally positive results have also been demonstrated for other disorders that are also characterized by high levels of anxiety, including functional urinary and bowel disorders, agoraphobia, and obsessive thoughts. Two hypotheses are presented, which attempt to explain how symptom prescription facilitates therapeutic change. Finally, some implications of symptom prescription for psychotherapy research and practice are briefly examined.
\end{abstract}

Descriptions of the therapeutic use of paradoxical symptom prescription have appeared under various names in different schools of psychotherapy over many decades. Included among these descriptors are the terms: negative practice (Dunlap, 1930), massed practice (Yates, 1958), paradoxical intention (Frankl, 1960, 1967, 1975), implosion (Stampfl \& Levis, 1967), symptom scheduling (Newton, 1968) and symptom prescription (Rohrbaugh, Tennan, Press, White Raskin, \& Pickering, 1977). Despite differences in their clinical approach and in the mechanisms presumed to underlie these constructs, they all involve some variation of a directive to clients to engage in the problematic behavior (or symptom) they are seeking to relieve. ${ }^{1}$

Given the unorthodox nature of these directives it is not surprising that their use was confined to those who discovered their supposed therapeutic effects. However, recently the use of paradoxical techniques, including symptom prescription, has become quite popular among therapists of many persuasions specializing in the treatment of individual problems. This growing trend to employ an apparently

'The foregoing does not, however, imply that because these various descriptions have a treatment component in common they can be explained by a common hypothesis.

Requests for reprints may be addressed to Joel Katz, Department of Psychology, McGill University, 1205 Docteur Penfield Avenue, Montreal, Quebec H3A IBI Canada. 
illogical treatment technique seems to be the result of several developments in the field of mental health.

The first relates to the decline in popularity of the psychoanalytic tradition, the evolution of behavior therapy, and the recent emergence of the cognitive-behavioral therapy school. These latter approaches place emphasis upon the empirical demonstration of the clinical efficacy of a specific technique prior to its acceptance and widespread use (Kazdin, 1979; Kazdin \& Wilcoxon, 1976). Secondly, the insistence that the scientific method be used to verify that a technique is therapeutically effective supported the emergence of eclectic approaches to psychotherapeutic practice (Smith, 1982), and fosters the pragmatic stance of using techniques that "work," even if their theoretical underpinnings are unclear.

A third development is reflected in the growing marital and family literature on brief, behaviorally-oriented, "strategic" approaches to treating couple and family problems (Andolfi, 1980; Haley, 1973, 1976, 1984; Madanes, 1981; SelviniPalazzoli, 1978; Stanton, 1981; Weakland, Fisch, Watzlawick, \& Bodin, 1974; Weeks \& L'Abate, 1982). The use of paradoxical prescriptions is central to the strategic approach (Weeks \& L'Abate; 1982), which emphasizes the issuing of tasks and directives that "work," regardless of how illogical they may appear to be. The current popularity of prescribing symptoms may thus reflect a discontent with traditional methods of treatment and concern with developing empirically testable alternative techniques.

This paper ı eviews the use of paradoxical symptom prescription in individual psychotherapy. In part one the concept of symptom prescription is defined and described with examples. Part two critically reviews clinical outcome studies on the efficacy of prescribing symptoms in cases characterized by varying degrees of anxiety. In a third section, two hypotheses are examined which attempt to explain how the prescribing of symptoms produces symptom reduction. Part four briefly examines some implications of symptom prescription for psychotherapy research and practice. Finally, several conclusions are drawn on the use of this paradoxical therapeutic technique.

\section{SYMPTOM PRESCRIPTION}

Prescribing the symptom is a commonly used paradoxical intervention for bringing about therapeutic change (Raskin \& Klein, 1976; Rohrbaugh et al., 1977; Weeks \& L'Abate, 1982). In its simplest form, symptom prescription involves an explicit directive, by the therapist, encouraging clients to maintain their problematic behavior or symptom. For example, a client complaining of difficulty falling asleep at night might be told to remain awake as long as possible; an individual troubled by obsessive ruminations could be directed to ruminate even more.

In practice, any one or more of a number of different elements of a symptom complex can be prescribed, including the cognitive, affective, behavioral, contextual, relational, attitudinal, and symbolic conponents (Zieg, 1980). For example, in the case of an individual complaining of obsessive ruminations, the therapist may prescribe the thoughts themselves (Solyom, Garza-Perez, Ledwidge, \& Solyom, 1972), or the subject matter of the thoughts (i.e., the behavioral counterpart) (Milan \& Kolko, 1982). In agoraphobics, symptom prescription may be directed at the cognitive component (e.g., Ascher, 1981), the patient being requested to bring 
about the feared disastrous consequence of prolonged, intense anxiety (e.g., heart attack, fainting, vomiting, "going crazy"), and/or at facilitating such physiological correlates of anxiety as sweating, blushing, or heart palpitations (Mavissakalian, Michelson, Greenwald, Kornblith, \& Greenwald, 1983). The choice of which element of a symptom complex to prescribe for a given client or problem has received little attention and appears to be a matter of clinical intuition and experience.

When therapists prescribe one or more of these elements of a symptom complex, often they simultaneously have clients attempt to alter certain parameters of the symptom. At times clients may be requested to exaggerate the symptom (Ascher, 1980). They may be directed to embellish the symptom by adding an aversive element to it so as to create an ordeal. This approach has been used by Erikson (Haley, 1984) in his treatment of the insomniac who was directed to remain awake and make use of the free time to catch up on his household chores by waxing and polishing the floors all night. Requesting a client to alter the frequency with which a symptom occurs has also been employed. The prescription to increase the frequency of a symptom is generally used with clients whose complaints appear to be maintained by their repeated, and unsuccessful attempts at controlling them (e.g., obsessional thoughts, tics, stuttering, insomnia) (Bogdan, 1982; Weakland, et al., 1974). Sometimes therapists prescribe a particular time of day when clients are to have their symptoms, or they allot a period of time in which the clients are to practice their symptoms. This latter approach has been used with depressed individuals (Beck \& Strong, 1982; Feldman, Strong, \& Danser, 1982) and severe procrastinators (Lopez \& Wambach, 1982; Wright \& Strong, 1982).

\section{CLINICAL OUTCOME STUDIES}

The literature on symptom prescription contains a number of remarkable claims of its effective use for a wide variety of clinical disorders. In a recent review, Stanton (1981) lists, as a "sampler," a total of 46 clinical disorders that have responded favorably to paradoxical interventions. Included among these are alcoholism, anorexia nervosa, anxiety disorders, chronic pain, depression, encopresis, enuresis, sexual problems, and schizophrenia. Weeks and L'Abate (1982) claim that there are literally hundreds of reports on the effective use of these techniques.

Unfortunately, despite the claims, the majority of the reports are anecdotal in nature, or they derive from uncontrolled case studies. There is, however, an emerging empirical literature, describing controlled case and group studies, which evaluates the effectiveness of symptom prescription in reducing the symptom in certain disorders characterized by anxiety, including insomnia, functional urinary retention and bowel dysfunction, bruxism, agoraphobia, and obsessive ruminations. ${ }^{2}$

\footnotetext{
${ }^{2}$ Most of the articles selected for review in this section were obtained from a computer search of Index Medicus (1980-1983) using each of the keywords "double-bind" and "paradox" in conjunction with "psychotherapy," from the Psychological Abstracts (1967-December, 1983) using "paradoxical techniques" and "double-bind interaction" respectively, in conjunction with "psychological techniques" as keywords. Studies were further selected for inclusion if even minimal control conditions prevailed. In such cases, however, the lack of adequate controls is noted. With the exception of the study by Mavissakalian et al. (1983), all examine the efficacy of symptom prescription for individual psychotherapy.
} 


\section{Insomnia}

The first study to empirically evaluate paradoxical intention ${ }^{3}$ as an effective therapy for sleep-onset insomnia was a multiple case study conducted by Ascher and Efran (1978). Five clients complaining of severe insomnia that had proved refractory to a 10 week behavioral program of systematic desensitization and covert conditioning were given a paradoxical directive to remain awake as long as possible instead of trying to fall asleep. In contrast to the previous 10 week period, all clients reported significant reductions in sleep onset latency sufficient to make additional treatment superfluous.

Relinger and his colleagues confirmed these initial positive findings with the addition of two controlled case studies (Relinger \& Bornstein, 1979; Relinger, Bornstein, \& Mungas, 1978). The Relinger and Bornstein (1979) study is particularly noteworthy as it highlights a potential confound that arises when using traditional counterdemand instructions to control for the effects of certain nonspecific factors. Relinger and Bornstein's subjects were presented with counterdemand instructions similar to those provided by Steinmark and Borkovec (1974), informing them that although the treatment (paradoxical intention) they were about to receive was effective, they should not expect any improvement until after it was over. These instructions were intended as a control procedure for the effects of expectancy and therapeutic demand, in that improvement occurring before the counterdemand period would provide evidence for the efficacy of paradoxical intention above and beyond that of these traditional "placebo" variables. Significant improvement on five of eight measures of insomnia occurred well within the counterdemand period for all subjects. At a 12 week follow-up, the mean reduction in sleep onset latency was $81 \%$ of (or about 90 minutes less than) the original baseline measures.

While these results support the effectiveness of symptom prescription, the possibility exists that, despite their intended effects, the counterdemand instructions issued to the subjects may actually have contributed to the treatment effect as they appear to be consistent with the paradoxical technique of restraining change (Rohrbaugh et al., 1977; Weeks \& L'Abate, 1982). According to this alternative hypothesis, improvement during the counterdemand (restraining) period would provide evidence for the effectiveness of restraining as a paradoxical technique, thus confounding the effects of the two paradoxical interventions (symptom prescription and restraining). It is true that for the purpose of the Relinger and Bornstein (1979) experiment, improvement under either hypothesis supports the effective use of paradox (despite the confound). But the possibility of construing counterdernand instructions as a paradoxical technique which predicts change to occur results in ambiguous findings and problems in interpretation.

Turner and Ascher (1979) followed up these positive findings obtained from case studies with the first well controlled group study which compared paradoxical intention, progressive relaxation, and stimulus control. They used a placebo control group based on a quasi-desensitization procedure designed by Steinmark and Bor-

sThe following terms are used interchangeably and refer to the procedure whereby the therapist directs the client to engage in his symptomatic behavior: massed practice, paradoxical directive, paradoxical injunction, paradoxical instruction, paradoxical intention, symptom prescription. 
kovec (1974), and a group of wait-listed insomniacs as controls. The finding that the paradoxical intention condition produced as much improvement as did the other two treatments (which already had established reputations as effective therapies) provided unequivocal support for paradoxical symptom prescription as an alternative and equally effective procedure for treating individuals complaining of insomnia.

Ascher and Turner $(1979,1980)$ have since furnished additional evidence supporting the use of paradoxical intention for sleep onset insomnia. Most recently, they compared the relative effects of two different rationales for symptom prescription, each of which has been effectively used in separate studies. The Type A rationale was a "straight-forward" explanation consistent with the authors' conceptualization of the theory underlying paradoxical intention, and has been successfully employed as a rationale in group studies (Ascher, 1979; Turner \& Ascher, 1979). Subjects receiving this rationale were informed that insomnia was brought about by their unsuccessful attempts to control the involuntary sleep process by actively trying to fall asleep. They were told that by attempting to remain awake as long as possible they would circumvent the performance anxiety usually generated by their repetitive, unsuccessful attempts to fall asleep. Type B rationale employed a "reframing procedure" (Watzlawick, Weakland, \& Fisch, 1974) that has been effective in controlled, single and multiple case studies (Ascher \& Efran, 1978; Relinger \& Bornstein, 1979; Relinger, Bornstein, \& Mungas, 1978). These subjects were told that a common cause of insomnia is the anxiety-provoking thoughts people experience while waiting to fall asleep. They were required to remain awake as long as possible in an effort to become aware of these disturbing thoughts, which were to serve as hierarchy items in a subsequent systematic desensitization program. The results revealed that subjects receiving the Type A rationale showed significantly less sleep disturbance than the waiting list controls on all five dependent measures, and greater improvement than the Type B and placebo control subjects on three of the five. Credibility ratings and ratings of therapist warmth were comparable for all groups. However, as Ascher and Turner themselves note, the Type $B$ rationale contained the implication that the paradoxical prescription was simply the data gathering phase of the treatment, with the actual therapy to follow at a later time. It is likely that the implicit demand characteristics created by this rationale precluded improvement much in the same way that clients who are explicitly informed that change is not expected to occur until a specified time conform to this expectation (Steinmark \& Borkovec, 1974). Given these considerations, it is probably wisest to refrain from a statement about the relative efficacy of reframing procedures until further controlled studies have been conducted. Nevertheless, these findings do provide additional support for the effectiveness of symptom prescription.

The one study that has failed to provide support for the use of symptom prescription as a viable treatment for sleep onset insomnia was a replication of the Turner and Ascher (1979) study, which compared paradoxical intention, stimulus control, and progressive relaxation (Turner \& Ascher, 1982). Whereas the two latter techniques proved effective in ameliorating the sleep disturbance, paradoxical instructions did not. However, the authors note that because of pretreatment differences in the severity of the sleep disturbance reported by the clients assigned to the three conditions, an unequivocal interpretation of these findings is not possible. Nevertheless, with the exception of this one study, there is, overall, suf- 
ficient evidence to warrant the conclusion that paradoxical symptom prescription is an effective treatment for individuals complaining of sleep onset insomnia.

\section{Psychogenic Urinay Retention and Bowel Dysfunction.}

Ascher (1979) has also provided initial support for the effective use of paradoxical intention in alleviating functional urinary retention that proved unresponsive to a conventional 10 week behavioral program. Five clients were given a paradoxical directive prohibiting them from urinating in a bathroom in which they experienced discomfort. They were directed to perform all the activities they normally engaged in when preparing to urinate (e.g., approach the urinal, open fly, etc.) but were explicitly restrained from doing so. Within six weeks, all clients reported a significant reduction, both in anxiety associated with urination, and in the latency to urinate. Improvement was maintained for four of the five clients at a six month follow-up. The fifth client, who reported to occasionally suffer from a relapse, claimed that by reinstating the paradoxical prescription he was effectively able to reduce his anxiety level. These initial findings suggest paradoxical prescription might prove to be the treatment of choice for psychogenic urinary retention when conventional methods fail.

In a single case study using an ABAB reversal design, Bornstein, Sturm, Retzlaff, Kirby, and Chong (1981) demonstrated the effective use of paradoxical instructions in ameliorating a condition of encopresis and chronic constipation. The patient was a nine-year-old boy with a four year history of bowel difficulty that had proved unresponsive to a variety of interventions. The child was instructed to engage in the usual behaviors which normally precede a bowel movement (e.g., enter the bathroom, let his trousers down, sit on the toilet seat), but was not to allow a bowel movement to occur. The results revealed a considerable decrease in the number of soilings and an increase in the number of appropriate bowel movements when the paradoxical instructions were in effect, and a return to baseline performance when they were subsequently (but temporarily) eliminated. Reinstating the paradoxical prescription with concomitant instructions to gradually fade out the number of daily visits to the bathroom resulted in appropriate behavior, which was maintained at a one-year follow-up.

\section{Bruxism}

Ayer and his colleagues (Ayer \& Gale, 1969; Ayer \& Levin, 1973; 1975) report the effective use of massed practice for eliminating nocturnal tooth clenching and grinding (bruxism). Patients were instructed to clench their teeth together as hard as possible for variable intervals throughout the day. According to a self-report measure of change, and by asking the patient's spouse, bruxism was found to decrease dramatically in most cases. However, these studies lack adequate control conditions and hence their findings should be viewed with caution, especially in the light of a study conducted by Heller and Forgione (1975). Using an objective, mechanical device to measure bruxism, these authors were unable to find posttreatment differences in the frequency of tooth grinding for patients receiving progressive relaxation, massed practice or for those who had been assigned to a no treatment control condition. Unfortunately, Heller and Forgione did not also obtain subjective measures of change from the patient and his or her spouse. 


\section{Agoraphobla}

Most recently, use of paradoxical symptom prescription has been evaluated as a potential treatment for agoraphobia (Ascher, 1981; Mavissakalian et al., 1983). In a particularly well designed and controlled experiment, Ascher (1981) compared the effects of paradoxical intention with in vivo graded exposure using changes in a behavioral approach test as the dependent measure. This involved traveling along a maximally discomforting route toward a target location until the subject experienced an increase in anxiety. At this point, subjects receiving graded exposure were instructed to return home immediately, whereas those in the paradoxical intention condition were to try to heighten the physiological experience of anxiety in an attempt to bring about the feared consequence (e.g., cardiac arrest, fainting, vomiting, "going crazy"). They were to remain there until the discomfort abated, and then had the choice of continuing along the route, or returning home. At the end of treatment, clients who had received paradoxical intention were able to travel significantly farther along a previously discomforting route than those treated with graded exposure. Furthermore, within group comparisons of baseline and treatment phases revealed significant gains on the behavioral approach test for subjects receiving paradoxical intention but no change for those treated with graded exposure.

Mavissakalian et al. (1983) compared self-statement training (Meichenbaum, 1977) with paradoxical intention in the treatment of 26 patients fulfilling the DSM III criteria for agoraphobia. Patients were assessed using a battery of behavioral, affective, and cognitive measures, including a 0.4 mile behavior approach test, tape recordings of their self-statements uttered during the approach test, and nine questionnaires measuring various dimensions of anxiety. They found paradoxical intention to be superior to self-statement training on four of six measures of fear and anxiety related specifically to agoraphobia. At a six month follow-up, however, these differences were no longer apparent due to the improvement of subjects in the self-statement group. Assessment of cognitions during the behavior approach test indicated that the number of self-defeating statements decreased from baseline to post-treatment for both groups, whereas the incidence of coping statements essentially remained at the baseline level for the self-statement training condition, and actually decreased for the paradoxical intention condition. These latter findings are especially interesting since they raise the possibility that the presence of coping statements may well contribute to the maintainence of the anxiety component in some agoraphobics. Ascher (1980) has discussed the potentially detrimental effects of such treatments whose procedures are designed to deal directly with certain anxiety disorders.

While these findings support the efficacy of paradoxical intention in treating the anxiety component of agoraphobia, because of a number of methodological and statistical problems, it is best to view these results with caution. For one, the effects of treatment credibility, therapist qualities, and other nonspecific factors were not assessed, and so it is not possible to rule out their differential effects across groups. Secondly, lack of a control group brings into question any conclusions regarding the efficacy of either paradoxical intention or self-statement training. Finally, use of a series of univariate ANOVAs (one for each dependent variable) to assess treatment outcome, instead of a multivariate ANOVA, has the effect of increasing the Type one error rate beyond its stated value, thus resulting in a 
greater number of "significant" findings than may actually be warranted. Nevertheless, despite its shortcomings, this study is important in that Mavissakalian et al. (1983) provide a test of the specificity of the two cognitive techniques. The diametrically opposed assumptions underlying these two approaches suggest that more than just "common factors" are involved in facilitating therapeutic change. In addition, these authors also assessed self-statements made during the actual behavioral approach test in an attempt to measure cognitive changes as they might have been occurring.

\section{Obsessive Thoughts}

There have been two controlled endeavors to apply paradoxical intention in order to reduce obsessive thoughts (Milan \& Kolko, 1982; Solyom et al., 1972). Solyom et al. (1972) compared the effects of paradoxical intention applied to a "target" thought with an untreated control thought in ten patients complaining of multiple obsessions. For half the subjects, the target thought was either eliminated or considerably reduced, while the control thought remained unchanged. Cognitions of three of the remaining patients were unchanged, and two were reported to be unable to implement the procedure. Despite its methodological shortcomings (Ascher, 1980; Weeks \& L'Abate, 1982), this study provides some support for paradoxical intention in eliminating obsessive thoughts.

Milan and Kolko (1982) reported the effective use of symptom prescription in the treatment of a 33-year-old woman with a ten year history of obsessional flatulence ruminations that had proved resistant to other forms of therapy. The patient reported an obsessional worry that she was constantly surrounded by an unpleasant odor of flatus, which became more intense as her level of anxiety increased. Following a four week baseline period in which weekly "average perceived flatus scores" were gathered, based on hourly ratings of her perceived flatus emmisions, a misconception correction procedure was introduced. This involved presenting the patient with concrete, scientific evidence, by means of gas chromatographic analyses, demonstrating the absence of malodorous flatus on her undergarments. When this procedure failed to reduce her obsessional ruminations, a paradoxical directive to intensify her flatus emissions was given, with an appropriate reframing rationale. Perceived flatus scores were found to decrease in the week following the introduction of the paradoxical directive, and were maintained at a one year follow-up.

Overall, symptom prescription appears to be a highly effective technique for facilitating therapeutic change. It is clear, from the work of Ascher and his colleagues, that paradoxical intention is an effective treatment for sleep onset insomnia; it may even prove to be the treatment of choice. Ascher has also provided initial support for the effective use of this paradoxical technique in clients complaining of psychogenic urinary retention, and those with agoraphobia. The evidence appears to be promising for patients with certain types of obsessional thoughts and equivocal in ameliorating nocturnal tooth grinding and clenching. 


\section{EXPLANATORY HYPOTHESES}

Two views are now offered to account for the generally positive results of paradoxical symptom prescription. The first is a general, and rather loosely formulated theory which attempts to explain paradoxical intention in terms of clients' struggle for interpersonal power, and their attempts to obtain the upper hand in the therapeutic relationship. In part, it is based on the notion that certain clients resist the therapist's catalytic efforts to induce therapeutic change. Much of the account that follows has been distilled from Haley's work (Haley, 1973, 1976, 1984) on "strategic" approaches to problematic behavior. The second view is a more specific formulation, originally advanced by Frankl (1960) and more recently, by Ascher (1980, 1981), which rests on the assumption that paradoxical intention works by interupting a self-perpertuated cycle of performance anxiety.

According to Haley (1976), in prescribing a symptom that the client already has, the therapist creates a situation that is confusing. The client perceives a contradiction in the therapist's messages, communicated at one or more levels of abstraction. When a client seeks professional help for a distressing problem or symptom, the context in which the therapeutic encounter takes place includes a general expectancy that some change will occur. Clients may logically expect that in order to improve they will have to change some aspect of their troublesome behavior. Clients also normally anticipate that their therapists will expect them to change. When the therapist, instead, encourages the client to persist in symptomatic behavior, the client is faced with two contradictory messages, simultaneousy defined by the therapeutic context with its change expectancy, and the symptom prescription which requests no change. The underlying paradoxical message is, "in order to change, remain the same". There is often, as well, a supplementary, related message which restrains the client from change. The directive states more explicitly, "stop yourself from changing", or, "in order to help you change, I must try to restrain you from changing"!

Telling a client to do what he is already doing also has an unsettling effect when the client attempts to act on the prescribed directive. According to Bateson, Jackson, Haley, and Weakland (1956), symptom prescription places the client in a "therapeutic double-bind", a "no lose" situation in which whatever is done, the outcome is beneficial. If clients comply with the directive and "have the symptoms," they have succeeded in gaining voluntary control over them. If they defy the directive, they no longer have the symptoms and the object of therapy has been achieved. This explanation is based on the idea that certain clients are more resistant to change than others (Haley 1976, Tennan et al., 1981). The reasons for this are varied. Change can be frightening since it predicts the unknown. Sometimes the "cure" can be more frightening than the disorder, as in the "flooding" of a phobic individual with the feared object. In some cases, an individual wants help, but does not want to change. In others, individuals do not want to change because they do not think they have a problem, such as an adolescent youth who is acting out. In still others, issues of secondary gain may prevent change despite the client's apparent willingness to improve. These "oppositional individuals" (Ascher \& Turner, 1980), "therapist killers," "therapy addicts" (Weeks \& L'Abate, 1982), "helprejecting complainers" (Tennan et al., 1981) resist most direct attempts at change. They defy the directives and fight the therapist's moves to help. Symptom pre- 
scription is believed to work (i.e., result in symptom reduction) because clients defy the injunction to do what they already are doing and therefore improve.

Recently, Tennan, Rohrbaugh, Press, and White (1981) have advanced what appears to be a more empirically testable model that incorporates much of Haley's view (and Ascher's view as well). These authors describe two categories of paradoxical prescriptions: compliance and defiance based directives. They offer different rationales for how the two types of directives work. Compliance based prescriptions are believed to work because the client attempts to carry out the directive, in the process of which he/she either gains control over the symptom, changes it in some other way, or loses it in the attempt to comply. For example, getting an agoraphobic client to have an anxiety attack in a discomforting situation allows him/her to experience the fear without struggling to overcome it (Ascher, 1981). Defiance based prescriptions are believed to work because the client defies the therapist's injunction. When issuing defiance based directives, the therapist, expecting that the client will rebel, attempts to mobilize the client's resistance in a strategic and deliberate way (e.g., by acting in an authoritarian, controlling manner, by coming on strong, by reducing the client's perception of free choice). As an example of a defiance based directive, a therapist might instruct a depressed client who is resentfully dependent upon, and enmeshed with, his family to continue his depressive behavior. The explanation would be given that in so doing, he would show his appreciation of his family by continuing to be such a considerate and helpful son to his parents, whose job of caring for him would be simplified. Stating it this way, the client would be most likely to resist.

According to Tennan et al. (1981) two client factors play a role in determining whether to issue a compliance or defiance based prescription. These are the client's level of reactance potential (resistance to change) and the extent to which the client perceives the prescribed symptom as "free" (voluntary). When reactance potential is high and the symptom is "free," the most effective strategy is a defiance based one. Alternately, when reactance is low and the behavior is "unfree," the authors suggest using a compliance based intervention. Research examining client reactance, and the client's perception of how voluntary his/her problem is, may prove helpful in elucidating the mechanisms responsible for change when symptom prescription works.

Ascher $(1980,1981)$ has proposed that for certain individuals with disorders characterized by high states of anxiety, their attempts at controlling the anxiety only lead to more. These disorders are maintained by the client's repeated and unsuccessful attempts to stave them off. According to Ascher (1980), after an initial attempt at controlling the anxiety, the individual monitors his/her state to determine whether the remedial effort has had its intended effect. The discovery that the anxiety has not changed increases it still further. Each successive attempt to reduce the anxiety has the opposite effect. This spiraling process is maintained, and reinforced with each attempt to escape or avoid the discomforting situation. Ascher has noted (1980) that with these individuals the therapist may unwittingly contribute to this spiraling process by introducing therapeutic measures designed to deal directly with the anxiety by controlling it (e.g., progressive relaxation, self-statement training). These attempts only serve to exacerbate the problem.

This self-perpetuating cycle is thought to be broken by introducing the paradoxical prescription to continue engaging in the troublesome behavior. Since attempts at control are no longer the object, the performance anxiety is effectively 
circumvented. The client's intention when entering the discomforting situation has changed from one of controlling an involuntary process, to one in which that process is anticipated and encouraged. In effect, the task of engaging in the prescribed behavior is incompatible with the experience of performance anxiety brought about by the individual's monitoring of his/her state after he/she has implemented a strategy designed to reduce the anxiety. It is incompatible because the client's task is no longer one of control, thus monitoring is precluded.

At the present time there is little in the way of empirical evidence to support either theoretical explanation of how change occurs when symptom prescription works. With the exception of the study by Ascher and Turner (1980), which examined the relative effects of two rationales for paradoxical intention most research efforts have been directed at demonstrating the baseline effectiveness of this paradoxical technique. Some (e.g., Ascher, 1981; Turner \& Ascher, 1979) have compared symptom prescription with already established techniques and with equally credible attention placebo control groups (e.g., Ascher \& Turner, 1979). However, the issue of what underlying mechanisms or treatment components are responsible for facilitating therapeutic change when prescribing the symptom works, has yet to be empirically addressed.

The two theories advanced are not mutually exclusive, and may even prove to be different expressions of the same operative mechanism. Many of the studies reviewed used anxious clients with resistant problems. They may just as easily be viewed as resistant clients with anxiety problems. Ascher's explanation stresses the repetitive attempts these clients make at controlling an involuntary process. Attempts at control at the interpersonal level at least, form the cornerstone of Haley's (1976) ideas on the resistant client. One difference between the two approaches to symptom prescription is that Ascher relies on compliance from his clients whereas Haley expects defiance. However, regardless of the nature of the prescriptions, paradoxical intention may operate by allowing clients to "choose" to relinquish their symptoms, and thus try out new more adaptive modes of functioning. Further research in which client resistance or reactance is assessed may prove helpful in ultimately choosing between these theories.

\section{IMPLCATIONS FOR PSYCHOTHERAPY RESEARCH AND PRACTICE}

The generally favorable results of symptom prescription raise a number of implications concerning future psychotherapy research and practice in this area. The first concerns the contentious issue of whether current therapies are more effective than nonspecific treatment (Critelli \& Neumann, 1984). The second considers the use of symptom prescription for other disorders which are also characterized by high levels of anxiety.

Traditional models of psychotherapy assume that there is an active ingredient specific to therapy, the effects of which can be demonstrated to exceed those derived from "placebo" variables or "common factors" such as expectancy for improvement, procedure and rationale credibility, demand for improvement, and a number of therapist qualities (Critelli \& Neumann, 1984; Kazdin \& Wilcoxon, 1976). On the other hand, a number of authors have argued that the therapeutic effects of current psychotherapies derive solely from these common factors (e.g., Frank, 1981; Shapiro, 1971).

The research strategy of equating common factors across groups in order to 
control for client improvement due to nonspecific effects has traditionally been consistent with the "specificity" assumption behind the techniques being evaluated; namely, that by equating these factors one is also optimizing treatment outcome effects for all groups involved. Thus, the strategy has been to look for treatment effects above and beyond those derived from traditional placebo variables. However, when one of the treatments being evaluated involves a defiance based paradoxical directive, the practice of equating common factors and the implicit assumption of simultaneously optimizing treatment outcome may no longer be mutually consonant. This is because when a therapist issues a directive which he/ she expects the client to defy, the client's perceptions of the credibility of the treatment rationale, therapist warmth, and other such common factors often must deliberately be manipulated so as to induce defiance. Weeks and L'Abate (1982) note the importance of modifying the client's level of reactance (or resistance) to a directive by acting in an authoritarian, controlling, and powerful manner when issuing a defiance based paradox. Along similar lines, Grinder and Bandler (1976) suggest "cross-communication", (interacting with the client in his non-dominant representational mode) as another way to increase and mobilize resistance. It is also apparent from Haley's (1973) descriptions of Milton Erikson's work, that many of Erkison's paradoxical prescriptions appear to require the deliberate bewilderment, anger, and frustration of the client in order that he/she not engage in the prescribed behavior.

Theoretically, then, one might expect a different configuration of common factor ratings to be associated with optimal outcome for each group. A group given a paradoxical prescription might be expected to rate, for example, the therapist as less warm, less attentive etc., and the rationale as less credible than a group receiving a more traditional, established intervention (including an attentionplacebo control group). Yet despite these "uncommon" and less favorable common factor ratings, one would still expect the group receiving the symptom prescription to equal or exceed the established therapy on outcome measures of therapeutic gain. Clearly, obtaining this pattern of results would argue in favor of factors other than traditional placebo variables as the source of therapeutic change.

The positive findings of paradoxical symptom prescription also suggest wider use of this technique in cases characterized by high anxiety. Ascher (1980) has suggested use of this technique for certain sexual disorders in which self-monitoring and performance anxiety play prominent roles in maintaining the problem. Certainly, this is an area in which controlled studies are needed. Along the same lines, the author is currently considering the potential for using this paradoxical technique with clients complaining of phantom limb pain. It is well established that this chronic pain syndrome is associated with excessive sympathetic nervous system activity, and is aggravated during times of emotional and physical stress (Melzack \& Wall, 1982). These patients often report having "bouts" or "attacks" of intolerable phantom pain which occur unpredictably and come to be anticipated with dread. On the surface, these attacks appear to be similar to the panic or anxiety attacks seen in agoraphobia. Giving these patients an appropriate rationale for increasing the phantom pain still further during these attacks may lead to symptom reduction according to Ascher's model.

Finally, the generally positive findings of the effectiveness of symptom prescription suggest that more widespread teaching and training of therapists in this paradoxical technique is indicated. 


\section{SUMMARY AND CONCLUSIONS}

This paper reviewed the clinical outcome literature on paradoxical intention with the aim of determining whether prescribing the symptom is an effective therapeutic technique. Overall, there is sufficient evidence to indicate that paradoxical symptom prescription effectively facilitates therapeutic change. This is particularly evident in cases of insomnia that proved resistant to other forms of treatment and seems to be true for difficult cases of functional urinary retention as well. The results from studies using patients with agoraphobia and those complaining of obsessive thoughts have also provided initial support for the efficacy of this paradoxical technique but this conclusion awaits further confirmation. Since the majority of the controlled outcome studies have been conducted by Ascher and his colleagues, there is the question of the generalizability of these findings. Further research by independent researchers is needed before this issue can be resolved.

Acknowledgement-I thank Dr. Myer Katz and Ms. Kathryn S. Hall for their helpful comments and discussions during the preparation of this manuscript.

\section{REFERENCES}

Andolfi, M. (1980). Family Therapy: An Interactional Approach. New York: Plenum Press.

Ascher, L. M. (1979). Paradoxical intention in the treatment of urinary retention. Behaviour Research and Therapy, 17, 267-270.

Ascher, L. M. (1980). Paradoxical intention. In A. Goldstein and E. B. Foa (Eds.), Handbook of Behavioral Intenentions. New York: John Wiley \& Sons.

Ascher, L. M. (1981). Employing paradoxical intention in the treatment of agoraphobia. Behaviour Research and Therapy, 19, 533-542.

Ascher, L. M., \& Efran, J. S. (1978). Use of paradoxical intention in a behavioral program for sleep onset insomnia. Journal of Consulting and Clinical Psychology, 46, 547-550.

Ascher, L. M., \& Turner, R. M. (1979). Paradoxical intention and insomnia: An experimental investigation. Behaviour Research and Therapy, 17, 408-411.

Ascher, L. M., \& Turner, R. M. (1980). A comparison of two methods for the adminstration of paradoxical intention. Behaviour Research and Therapy, 18, 121-126.

Ayer, W. A., \& Gale, E. N. (1969). Extinction of bruxism by massed practice therapy: report of a case. Joumal of the Canadian Dental Association, 35, 492-494.

Ayer, W. A., \& Levin, M. P. (1973). Elimination of tooth grinding habits by massed practice therapy. Journal of Periodontology, 44, 569-571.

Ayer, W. A., \& Levin, M. P. (1975). Theoretical basis and application of massed practice exercises for the elimination of tooth grinding habits. Journal of Periodoniology, 46, 306-308.

Bandura, A. (1977). Toward a unifying theory of behavior change. Psychological Review, 84, 191-215.

Bateson, G., Jackson, D., Haley, J., \& Weakland, J. (1956). Toward a theory of schizophrenia. Behavioral Science, 1, 251-264.

Beck, J. T., \& Strong, S. R. (1982). Stimulating therapeutic change with interpretations: A comparison of positive and negative connotation. Journal of Counseling Psychology, 29, 551-559.

Bogdan, J. L. (1982). Paradoxical communication as interpersonal influence. Family Process, 21, 443452.

Bornstein, P. H., Sturm, C. A., Retzlaff, P. D., Kirby, K. L., \& Chong, H. (1981). Paradoxical instruction in the treatment of encopresis and chronic constipation: An experimental analysis. Journal of Behavior Therapy and Experimental Psychiatry, 12, 167-170.

Critelli, J. W., \& Neumann, K. F. (1984). The placebo: Conceptual analysis of a construct in transition. American Psychologist, 39, 32-40.

Dunlap, K. (1930). Repetition in the breaking of habits. Science Monthly, 30, 66-77. 
Emmelkamp, P. M. G. (1982). Anxiety and Fear. In A. S. Bellack, M. Hersen, \& A. E. Kazdin (Eds.), International Handbook of Behavior Modification and Therapy. New York: Plenum Press.

Feldman, D. A., Strong, S. R., \& Danser, D. B. (1982). A comparison of paradoxical and nonparadoxical interpretations and directives. Journal of Counseling Psychology, 29, 572-579.

Frank, J. D. (1981). Therapeutic components shared by all psychotherapies. In J. H. Harvey \& M. M. Parks (Eds.), Psychotherapy Research and Behavior Change. Washington: American Psychological Association Inc.

Frankl, V. E. (1960). Paradoxical intention: A logotherapeutic technique. American Journal of Psychotherapy, 14, 520-535.

Frankl, V. E. (1967). Psychotherapy and Existentialism: Selected Papers on Logotherapy. New York: Washington Square Press.

Frankl, V. E. (1975). Paradoxical intention and dereflection. Psychotherapy: Theory, Research and Practice, $12,226-237$.

Grinder, J., \& Bandler, R. (1976). The Structure of Magic Vol. II. Palo Alto: Science and Behavior.

Haley, J. (1973). Uncommon Therapy: The Psychiatric Techniques of Milton H. Erikson, M.D. New York: Norton.

Haley, J. (1976). Problem-Solving Therapy. San Francisco: Jossey-Bass.

Haley, J. (1984). Ordeal Therapy. San Francisco: Jossey-Bass.

Heller, R. F., \& Forgione, A. G. (1975). An evaluation of bruxism control: Massed negative practice and automated relaxation training. Journal of Dental Research, 54, 1120-1123.

Kazdin, A. E. (1979). Fictions, factions and functions of behavior therapy. Behavior Therapy, 10, 629654.

Kazdin, A. E., \& Wilcoxon, L. A. (1976). Systematic desensitization and nonspecific treatment effects: A methodoldogical evaluation. Psychological Bulletin, 83, 729-758.

Lopez, F. G., \& Wambach, C. A. (1982). Effects of paradoxical and self-control directives in counseling. Journal of Counseling Psychology, 29, 115-124.

Madanes, C. (1981). Strategic Family Therapy. San Francisco: Jossey-Bass.

Mavissakalian, M., Michelson, L., Greenwald, D., Kornblith, S., and Greenwald, M. (1983). Cognitivebehavioral treatment of agoraphobia: Paradoxical intention vs self-statement training. Behaviour Research and Therapy, 21, 75-86.

Meichenbaum, D. H. (1977). Cognitive-Behaviour Modification: An Integrative Approach. New York: Plenum Press.

Melzack, R., \& Wall, P. D. (1982). The Challenge of Pain. New York: Penguin Books.

Milan, M. A., \& Kolko, D. J. (1982). Paradoxical intention in the treatment of obsessional flatulence ruminations. Journal of Behavior Therapy and Experimental Psychiatry, 13, 167-172.

Newton, J. R. (1968). Considerations for the psychotherapeutic technique of symptom scheduling. Psychotherapy: Theory, Research and Practice, 5, 95-103.

Raskin, D. E., \& Klein, Z. E. (1976). Losing a symptom through keeping it: A review of paradoxical treatment techniques and rationale. Archives of General Psychiatry, 33, 548-555.

Relinger, H., \& Bornstein, P. H. (1979). Treatment of sleep onset insomnia by paradoxical instruction: A multiple baseline design. Behavior Modification, 3, 203-222.

Relinger, H., Bornstein, P. H., \& Mungas, D. M. (1978). Treatment of insomnia by paradoxical intention: A time series analysis. Behavior Therapy, 9, 955-959.

Rohrbaugh, M., Tennan, H., Press, S., White, L., Raskin, P., \& Pickering, M. (1977). Paradoxical strategies in psychotherapy. Paper presented at the American Psychologist Association, San Francisco.

Selvini-Palazzoli, M. (1978). Self-Starvation. New York: Jason Aronson.

Shapiro, A. K. (1971). Placebo effects in medicine, psychotherapy, and psychoanalysis. In A. E. Bergin \& S. L. Garfield (Eds.), Handbook of Psychotherapy and Behavior Change. New York: John Wiley \& Sons.

Smith, D. (1982). Trends in counseling and psychotherapy. American Psychologist, 37, 737-746.

Solyom, L., Garza-Perez, J., Ledwidge, B., \& Solyom, C. (1972). Paradoxical intention in the treatment of obsessive thoughts: A pilot study. Comprekensive Psychiatry, 13, 291-297.

Stampfl, T., \& Levis, D. (1967). Essentials of implosion therapy: A learning theory-based psychodynamic behavioral therapy. Joumal of Abnormal Psychology, 72, 496-503.

Stanton, M. (1981). Strategic approaches to family therapy. In A. S. Gurman \& D. P. Kniskern (Eds.), Handbook of Family Therapy. New York: Brunner/Mazel.

Steinmark, S. W., \& Borkovec, T. D. (1974). Active and placebo treatment effects on moderate insomnia under counterdemand and positive demand instructions. Journal of Abnormal Psychology, 83, 157163. 
Tennan, H., Rohrbaugh, M., Press, S., \& White, L. (1981). Reactance theory and therapeutic paradox: A compliance-defiance model. Psychotherapy: Theory, Research and Practice, 18, 14-22.

Turner, R. M., \& Ascher, L. M. (1979). Controlled comparison of progressive relaxation, stimulus control, and paradoxical intention therapies for insomnia. Journal of Consulting and Clinical Psychology, 42, 500-508.

Turner, R. M., \& Ascher, L. M. (1982). Therapist factor in the treatment of insomnia. Behaviour Research and Therapy, 20, 33-40.

Watzlawick, P., Weakland, J. H., \& Fisch, R. (1974). Principles of Problem Formation and Problem Resolution. New York: W. W. Norton.

Weakland, J. H., Fisch, R., Watzlawick, P., \& Bodin, A. (1974). Brief Therapy: Focused problem resolution. Family Process, 13, $141-158$.

Weeks, G. R., \& L'Abate, L. (1982). Puradoxical Psychotherapy: Theory and Practice with Individuals, Couples, and Families. New York: Brunner/4azel.

Wright, R. M., \& Strong, S. R. (1982). Stimulating therapeutic change with directives: An exploratory study. Journal of Counseling Psychology, 29, 199-202.

Yates, A. J. (1958). The application of learning theory to the treatment of tics. Journal of Abnormal and Social Psychology, 56, 175-182.

Zeig, J. (1980). Symptom prescription techniques. Clinical applications using elements of communication. American Joumal of Clinical Hypnosis, 23, 23-33. 